\title{
Farewell to all
}

\section{Associate Professor John Lamp}

The time has come for me to move into a new phase of my life - retirement - and for AJIS to move into a new phase of its development.

I first came to academia at the age of 40 , after a varied work life, over which we shall draw a discrete veil.

In 1994, at the request of colleagues at the University of Tasmania, I began a list of IS journals we could publish in. Very rapidly this moved on to the Web, and developed into the Index of Information Systems Journals. It was because of that Web expertise that I became associated with the Australian Council of Professors and Heads of Information Systems, even though it was another 20 years before I actually became formally eligible as an Associate Professor.

In 1998 I moved to Geelong campus of Deakin University, which was about as close as I wanted to get to Melbourne. The Index, as well as the ACPHIS, AAIS, and other websites were physically hosted on a machine in my office. When the Excellence in Research for Australia project was launched, I created an SQL database of journals, rather than use the 35,000 line Excel spreadsheet that Canberra had provided. Following a random thought, I made the database generally available through my website. The subsequent 70,000 hits per month made it Deakin's highest profile web server, which did not go unnoticed by Deakin's IT services, who migrated my systems to official Deakin machines.

In 2013 I became Editor in Chief of AJIS. At the time I took up the position, AJIS, like so many other journals, was coming to grips with the changes that were, and still are, impacting on academic journals around the world. On the technical side there was the issue of an online presence and what that should look like both aesthetically and operationally, On the specific journal side, of attracting, processing and delivery of articles, the impact of the revolution in copyright and intellectual property and even whether journals still had a place in academic publishing.

I began a number of changes, focusing on increasing AJIS' profile, moving to a fully online journal and converting to a Green Open Access journal.

On the profile side,

- $\quad$ Successfully submitted AJIS to twenty Australian and international indexes and ranking schemes

- $\quad$ Linked to ORCID author identification

- $\quad$ Published quarterly Calls for Papers on the major IS mailing lists

- $\quad$ Established a Twitter channel for AJIS

- $\quad$ Established an AJIS Facebook page

- Increased the rigor involved with DOIs and added a QR code to each article, linking it to the full journal entry for that article

- $\quad$ Modernised the look of the AJIS website and articles 
- $\quad$ Publicised each article as it was released, to provide article by article publicity and build AJIS' profile

- Participated in the ACIS Doctoral Consortium to increase the students' understanding of the academic publication process and to encourage their participation as reviewers as well as authors

Specific AJIS improvements included

- Dropping six-monthly print publication in favour of online "publish on finalisation" to reduce publication delays and highlight each article as it became available

- $\quad$ Developing internal FAQs for Section Editors and submissions for Special Sections

- Introducing Post Publication Reviews and Research Notes sections

- $\quad$ Participating in a dark archive to preserve, and keep available, AJIS articles, should the journal ever fold or suffer catastrophic data loss

Some of the outcomes from these activities include

- Increasing the h-index of the journal, measured over its full life, by nearly $50 \%$ from 30 to 44

- Increasing Scimago's h-index which is measured over the past 10 years of data, by $100 \%$ to 15

- $\quad$ Boosting AJIS article downloads from about 700 per month in 2015 to over 5,000 per month in 2020

- $\quad$ Boosting new user accesses from about 65 per day (2014) to 310 per day (2020)

- Increasing monthly direct accesses to AJIS from 905 (2014) to 4,027 (2020), now nearly double the accesses by search engines.

- $\quad$ Being awarded the Directory of Open Access best practice seal

- $\quad$ Drastically improving external citations as measured by Scimago

- $\quad$ Attracting international recognition by initiating a section Research on Indigenous Use of Information and Communication Technologies

None of this has been the work of me alone. In doing this, I have been supported by AJIS' Advisory Board, composed of representatives of the Australasian Association for Information Systems, the Australian Council of Professors and Heads of Information Systems, and the Professors and Heads of Information Systems, New Zealand.

It is impossible for any academic journal to exist without a talented and committed body of editors and reviewers. Over the past six years I have seen the numbers of our editors and reviewers increase and attract members from outside the Australasian area as our reputation grew. 
Thank you all, the growth and development of AJIS would not have been possible without you.

AJIS was established in 1993 by Rob McGregor and has become a major part of the Australasian Information Systems community. Since then, it has had a number of editors:

$\begin{array}{ll}1993-2005 & \text { Rob McGregor } \\ 2006-2007 & \text { Craig McDonald } \\ 2008-2011 & \text { Jon Heales } \\ 2012-2013 & \text { Kathy Lynch } \\ 2014-2020 & \text { John Lamp }\end{array}$

It has been a privilege to be counted as one of those people. From 2021, Professor Karl Kautz will take on the role of Editor in Chief, and I wish him well for the future.

As for me, I look forward to devoting more time to recording and broadcasting Australian music, and adding to my collection of mechanical calculators. Maybe I'll even get that Meccano “Mini Difference Engine" built.

Copyright: (c) 2020 Lamp. This is an open-access article distributed under the terms of the Creative Commons Attribution-NonCommercial 3.0 Australia License, which permits noncommercial use, distribution, and reproduction in any medium, provided the original author and AJIS are credited.

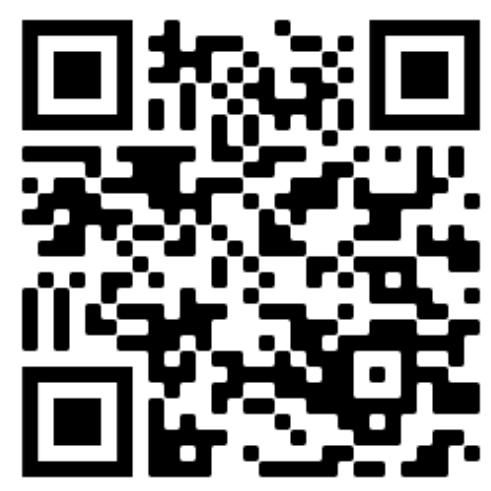

